\title{
Article \\ Peri-Implant Tissue Behaviour Next to Different Titanium Surfaces: 16-Year Post-Trial Follow-Up
}

\author{
Francesca Delucchi ${ }^{1, *}$, Enrico Pozzetti ${ }^{1}$, Francesco Bagnasco ${ }^{1}$, Paolo Pesce ${ }^{1}{ }^{1}$, Domenico Baldi ${ }^{1}$, Francesco Pera ${ }^{2}$, \\ Nicolò Di Tullio ${ }^{1}{ }^{1}$, Paolo Pera ${ }^{1}$ and Maria Menini ${ }^{1}$ (D) \\ 1 Department of Surgical Sciences (DISC), Division of Prosthodontics and Implant Prosthodontics, \\ University of Genova, 16132 Genova, Italy; enrico.pozzetti.96@icloud.com (E.P.); fcbagna5@hotmail.it (F.B.); \\ paolo.pesce@unige.it (P.P.); domenico.baldi@unige.it (D.B.); nicolo.ditullio@gmail.com (N.D.T.); \\ paolopera@unige.it (P.P.); maria.menini@unige.it (M.M.) \\ 2 CIR-Dental School, University of Turin, 10126 Turin, Italy; francesco.pera@unito.it \\ * Correspondence: francesca.delucchi@edu.unige.it; Tel.: +39-010-353-7421
}

Citation: Delucchi, F.; Pozzetti, E.; Bagnasco, F.; Pesce, P.; Baldi, D.; Pera, F.; Di Tullio, N.; Pera, P.; Menini, M. Peri-Implant Tissue Behaviour Next to Different Titanium Surfaces: 16-Year Post-Trial Follow-Up. Appl. Sci. 2021, 11, 9625 . https://doi.org/ 10.3390/app11209625

Academic Editor: Gabi Chaushu

Received: 30 June 2021

Accepted: 11 October 2021

Published: 15 October 2021

Publisher's Note: MDPI stays neutral with regard to jurisdictional claims in published maps and institutional affiliations.

Copyright: (c) 2021 by the authors. Licensee MDPI, Basel, Switzerland. This article is an open access article distributed under the terms and conditions of the Creative Commons Attribution (CC BY) license (https:// creativecommons.org/licenses/by/ $4.0 /)$.
Abstract: The present post-trial follow-up investigated the influence of titanium implants with different surface treatments on clinical behavior of soft and hard peri-implant tissues. Each of the 18 included patients received at least two adjacent implants: one control implant with a dual acidetched (DAE) surface in their apical portion and a machined coronal part, and one test implant with a DAE surface up to its coronal portion. Peri-implant bone level change (BLC), probing depth (PD), bleeding on probing (BOP) and plaque index (PI) were recorded. A total of 42 implants was inserted. The mean follow-up period was 9.3 years (range: 5-16 years) and there were six dropouts. No implant failed. Moderate crestal bone remodeling occurred during the first year after implant insertion, with lower bone loss next to test implants compared to control ones ( $0.80 \mathrm{vs} .1 .39 \mathrm{~mm}$; $p=0.002)$. This difference was also detected at the 5- $(p=0.011), 6-(p=0.008)$ and 7-year followup appointment $(p=0.027)$. No statistically significant differences were found in bone resorption between implants rehabilitated with ceramic vs. composite resin veneering material. No statistically significant differences were detected between test and control implants for BOP, PI, and PD at any time point. The results of the present study suggest that DAE surfaces reduce peri-implant bone loss in the initial phase of healing compared to machined surfaces, while they do not significantly affect soft peri-implant tissue and bone maintenance in the long-term. In conclusion, the minimally rough surfaces favour peri-implant bone maintenance and their effect is greater in the first year post implant insertion.

Keywords: dental implants; surface properties; titanium; bone resorption; prospective studies

\section{Introduction}

In the last decades, there has been an ongoing effort in improving the interface between dental implants and bone through modifications of the implant itself at macro-, micro- and nano-levels [1,2].

Micro-properties of implant surfaces can influence the structural and functional interface between implant and bone, and this has been suggested to allow the shortening of healing and restorative times. In fact, being directly in contact with hard and soft peri-implant tissues, implant surface plays a crucial role in the biological response of the bio-environment, affecting cellular behaviour and molecular interactions [3-6]. Intrinsic characteristics of the implant surface may affect the bone-implant interface, and influence the inflammatory response subsequent to implant insertion $[7,8]$.

According to Albrektsson and Wennerberg, implant surfaces can be divided into three different types of roughness: smooth $(\mathrm{Sa}<0.5 \mu \mathrm{m})$, machined/minimal (Sa: $0.5-1 \mu \mathrm{m})$, moderate $(1.0-2.0 \mu \mathrm{m})$, and rough $(>2.0 \mu \mathrm{m})$, with moderately rough surfaces showing stronger bone responses than the others [9]. 
Rough-surfaced titanium implants demonstrated a higher percentage of BIC (boneimplant contact) in comparison to those with a smoother surface $[10,11]$. This can enhance the removal torque, improving primary and long-term stability of dental implants [12].

In a recent systematic review of the Literature, Kligman et al. [3] underlined the osteogenic potential of rough dental implant surfaces, the latter facilitating the migration, adhesion, and proliferation of osteogenic and fibroblastic cells. A consensus report published in 2009 stated that "moderately rough and rough surfaces provide enhanced bone integration compared with smooth and minimally rough surfaces" [13].

There is an increasing promotion of new engineered designs of implant surface, and several techniques are available today to increase surface roughness. Among the physical modifications the following can be cited: sandblasting, plasma spray, magnetron co-sputtering, wire electrical discharge machining, thermal treatment, laser surface modification, non-thermal plasma and ultraviolet (UV) functionalization, etc. [14,15].

In the present study, acid-etched surfaces were used. Acid etching by strong acids is a commonly used chemical treatment to increase roughness and modify surface properties. According to a recent study by Mangano et al. [16], dual acid-etched (DAE) surfaces increased peri-implant endosseous healing properties in the native bone of the examined posterior maxilla, showing improved histological behaviour and histomorphometric bone response, and higher rates of removal torque, in comparison to machined surfaces.

It has been estimated that implant osseointegration is achieved when implant surface roughness is at least 1-1.5 $\mu \mathrm{m}$ [3]. However, at the same time, the increased roughness can facilitate bacterial adhesion and biofilm accumulation, especially in case of peri-implant tissue recession, with consequent exposure of the rough surface of the implant neck into the oral cavity [17].

Some studies have indicated that below a certain critical roughness of implant surface, called "threshold $\mathrm{R}(\mathrm{a})$ " $(0.2 \mu \mathrm{m})$, no further reduction of bacterial accumulation could be expected, and there is not any major impact on the supra- and subgingival microbial composition $[18,19]$.

Some authors have related plaque accumulation to the development of peri-implantitis, and considered plaque control the most important way to prevent peri-implant disease and implant failure [20-22]. However, there is a lack of evidence about a clear effect of implant surface on the onset of peri-implantitis [23].

Other recent studies $[24,25]$ have shown that, even if a correlation between plaque accumulation and mucositis can be found, this does not apply to peri-implantitis.

Bone resorption and so called periimplantitis have a multifactorial etiology and are influenced by a multitude of factors besides the implant features, including characteristics of the receiving site, surgical technique, prosthodontic material and design, individual susceptibility of the host (e.g., history of periodontitis), systemic conditions (e.g., diabetes mellitus, positive interleukin-1 genotype, uncontrolled HIV positivity, intravenous bisphosphonate, immunosuppressants), and behavioral factors (e.g., smoking, parafunction, adherence to supportive therapy), etc. All these conditions can potentially affect oral tissues, interfering with implant healing and bone maintenance over time [26-29].

In the current literature, several studies investigated the clinical outcomes of implants with different surface modifications, but most of them were parallel arm clinical trials [30] or retrospective studies [31].

There is a lack of randomized controlled clinical trials (RCT) designed according to a split-mouth method investigating the clinical performances of implants with different titanium surfaces. There is also a lack of clinical studies with a long-term follow-up. In particular, randomised controlled clinical trials typically have a relatively brief in-trial follow-up period which can underestimate the effects of a device and fail to detect longterm outcomes, which may take years to appear [32].

The aim of the present post-trial follow-up RCT was to report the 8- and 16-year soft and hard peri-implant tissues outcome parameters, comparing titanium dental implants 
with two different types of implant surfaces in their coronal portion: dual acid etched (DAE) and machined.

\section{Materials and Methods}

A sample of 18 patients (12 men, 6 women) with a mean age of 62.44 years (range: 44 to 76 years) at the time of recruitment referred to the Division of Implant and Prosthetic Dentistry (Department of Surgical Sciences, DISC) of the University of Genoa (Italy), and requiring the insertion of at least two adjacent implants, was included in this prospective clinical study.

A first cohort of 8 patients was treated between April 2005 and March 2007 (Group 1) [26,27], while the remaining 10 patients were later rehabilitated between March 2013 and July 2014 (Group 2) [28,29].

The present post-trial follow-up reports the clinical outcomes measured in both the cohorts of patients at their last follow-up appointment, that is up to 16 years for Group 1 and up to 8 years for Group 2.

The inclusion criteria were the same for the two cohorts of patients and are listed below:

- Good systemic health with no contraindications to oral surgery [33,34]: patients with an uncontrolled medical condition such as diabetes mellitus, immune suppression, intravenous or oral bisphosphonate medication, oro-facial cancer, chemotherapy or head and neck radiotherapy, and infarct during the preceding 6 months were excluded;

- $\quad$ No history of periodontal disease;

- $\quad$ Partial edentulism to be rehabilitated with at least two adjacent implants;

- Natural teeth or fixed prostheses supported by natural teeth as opposite dentitions (no removable prosthesis as antagonist);

- $\quad$ Teeth in treated areas had been extracted at least 1 year before;

- $\quad$ No heavy smokers ( $\geq 20$ cigarettes/day).

Baseline characteristics of the two cohorts of patients are reported in Table 1. Only two patients were smokers (one in Group 1 and one in Group 2) and they both reported to smoke two to three cigarettes/day.

Table 1. Baseline characteristics of the two cohorts of patients.

\begin{tabular}{ccc}
\hline & Group 1 & Group 2 \\
\hline $\mathrm{N}^{\circ}$ of patients & 8 & 10 \\
\hline $\mathrm{N}^{\circ}$ of implants & 20 & 22 \\
\hline Mean age (SD) (years) & $59.8(44-73)$ & 64.6 (52-76) \\
\hline Gender (n. of patients) & Men 1 & 5 \\
& Women 7 & 5 \\
\hline Smokers (n. of patients) & 1 & 1 \\
\hline Arch (n. of implants) & Maxilla 10 & 12 \\
\hline Implant site & Mandible 10 & 10 \\
\hline & Anterior 1 & 1 \\
\hline Implant length (n. of implants) & Posterior 19 & 21 \\
\hline Implant diameter (n. of implants) & 10 mm 9 & 10 \\
\hline
\end{tabular}

This research project was performed in agreement with the World Medical Association Helsinki Declaration. All treatments were approved by the local Ethical Committee of the University of Genoa (Approval Number: 21084). 
The manuscript was edited following the "Strengthening the Reporting of Observational Studies in Epidemiology" (STROBE) statement [35].

All the participants were thoroughly informed about the intervention and signed a written consent to the planned procedures. They also agreed to return for the required recall appointments.

All the patients were rehabilitated with fixed partial prostheses (no single crowns), supported by at least 2 implants into an edentulous quadrant following identical surgical procedures in all the clinical cases.

Three patients received 4 implants (all implants were in the same hemiarch), while the remaining fifteen patients received 2 implants each, for a total of 42 dental implants inserted (21 for both test and control groups) and 18 prostheses.

The surgical access was provided by mucoperiosteal flaps at the ridge crest (or slightly palatal to it) with buccal relieving incisions, and the crestal bone was flattened in case of need. The implant restorative platform was put at the level of crestal bone. No regenerative surgery procedures were performed at the implant sites.

Two different types of external hexagon implants were used. In fact, each edentulous area received at least one Osseotite (Biomet 3i, Palm Beach Gardens, FL, USA) and one Full Osseotite (Biomet 3i) implant (Figure 1), alternately placed.

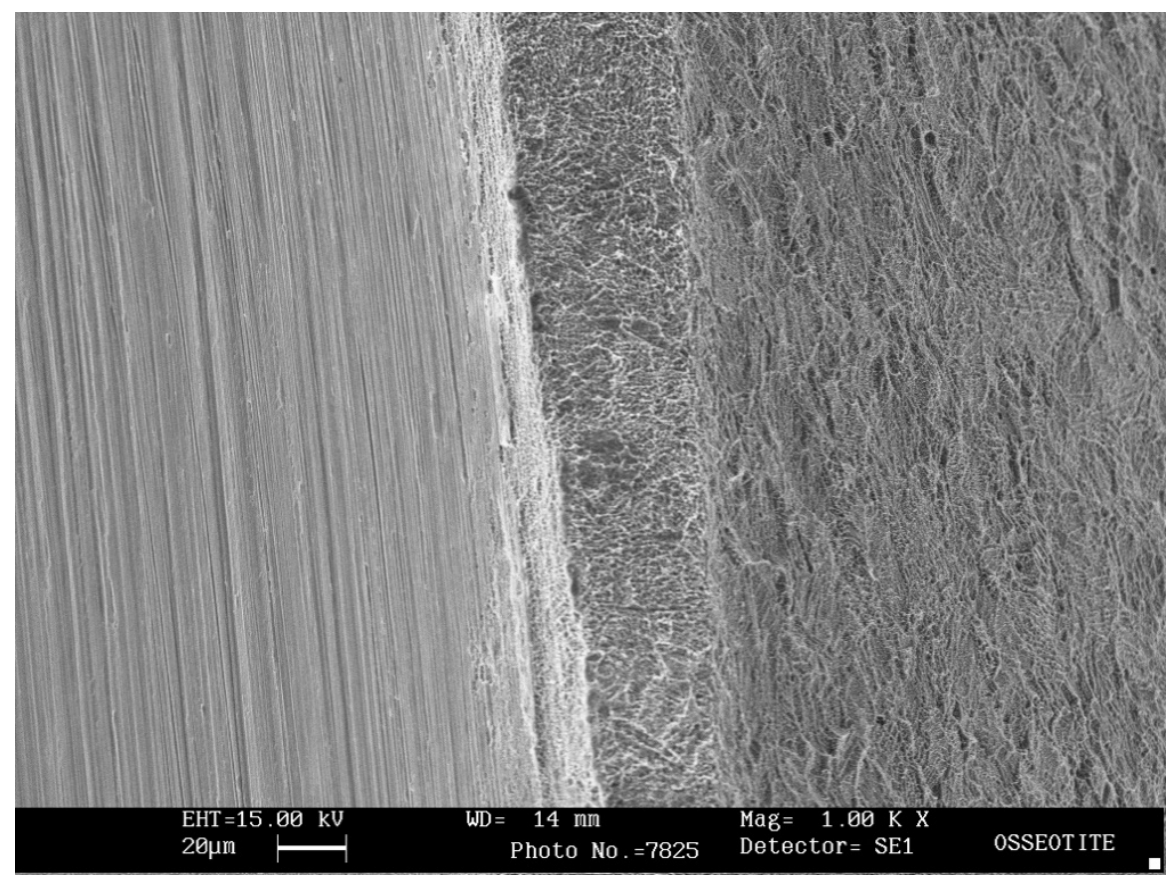

Figure 1. Scanning electron microscope (SEM) image (1000× magnification) showing the transition from the coronal machined surface (on the left) to the dual acid-etched surface (on the right) of the OSS implant with a hybrid design.

Osseotite implants (OSS, control group) are implants made of commercially pure titanium (Grade IV) treated with a specific, proprietary dual acid-etching (DAE) protocol. However, the coronal portion ( $3 \mathrm{~mm}$ ) of the surface is machined ("hybrid" design).

Full Osseotite implants (FOSS, test group) have the same macro- and micro-structure of OSS implants, except that the entire surface is treated with the company's DAE protocol (Figure 1).

The implants had a variable length of 10, 11.5 or $13 \mathrm{~mm}$ (depending on the available bone) and a diameter of $4 \mathrm{~mm}$.

The specific allocation of OSS and FOSS implants was determined by simple randomization, drawing lots to establish the assignment of FOSS implant to the mesial or distal side of the edentulous area to be rehabilitated. Implants were assigned specific number codes for blinding as described in a previous paper [26]. The statistician was blinded as 
well as the patient and the researcher measuring bone level. The clinician making the clinical assessments was blinded only after prostheses delivery, while before this phase the aspect of the healing abutments (machined or acid-etched) made blinding impossible.

The implants were inserted maintaining a minimum of $1.5 \mathrm{~mm}$ [36] of bone thickness on the buccal and lingual side; the two adjacent implants had a minimum inter-implant distance of $3 \mathrm{~mm}$ [37], and the distance between implants and adjacent teeth was not less than $1.5 \mathrm{~mm}$ [38].

In the upper jaw a total of 22 implants were inserted: 21 in the posterior area (premolar or molar) and 1 in the anterior area (canine or incisive). In the inferior jaw, a total of 20 implants were inserted: 19 in the posterior and 1 in the anterior region respectively.

At the time of surgery, healing abutments were connected to implants, according to a single-stage approach. OSS implants received standard machined surface healing abutments, while DAE surfaced abutments were connected to FOSS implants. The latter were custom made by Biomet $3 \mathrm{i}$ for this clinical study (Figure 2a).

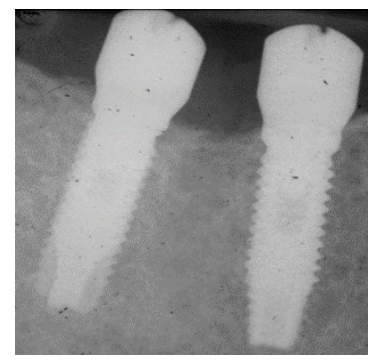

(a)

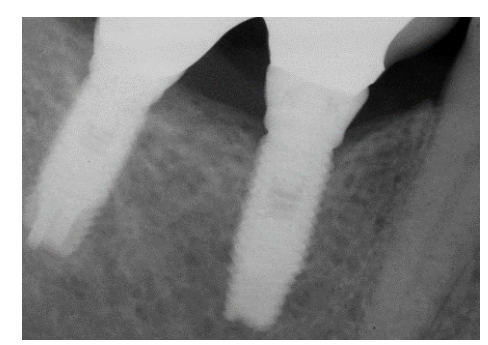

(b)

Figure 2. (a) Example of a periapical radiograph taken immediately after implant placement. A standard machined surface healing abutment was connected to the control implant (OSS, on the right). The test implant (FOSS, on the left) was provided with a healing abutment treated with the company's DAE protocol; (b) radiograph of the same implants 16 years after implant insertion.

The implants were treated with a conventional delayed loading after 4-5 months (mean 20 weeks) of healing. At this time, analogic impressions were taken in order to fabricate provisional prostheses, that were inserted 1 week later.

About 5-6 months (mean 24 weeks) after implant insertion definitive fixed prostheses provided with a cast metal framework were delivered (Figure $2 b$ ). Two different aesthetic veneering materials were employed: metal-ceramic in the first group treated (Group 1) and metal-composite in the cohort of patients treated more recently (Group 2). In fact, the prosthodontic protocol applied by the authors changed following their studies on the shock-absorption capacity of restorative materials [39]. Cantilevered extensions were avoided and a careful occlusal control was performed at prosthesis delivery.

Both for provisional and definitive impressions, a pick-up impression technique with polyvinyl siloxane was employed (Express STD, 3M ESPE).

Periapical radiographs were also taken to evaluate the fit of prosthetic substructures to the implants before prostheses delivery.

The patients were instructed to perform an appropriate domiciliary oral hygiene (a medium bristle toothbrush and sponge floss were suggested) and were recalled for semestral professional hygienic sessions.

A previous paper describes in more detail the recall protocol performed during the first year from implant allocation [26].

\subsection{Radiographic Assessment of Interproximal Bone Level Change (BLC)}

Interproximal bone level was investigated through standardized periapical radiographs, taken at baseline (immediately after implant insertion), 3 and 6 months, then 1, 5, $6,7,8,15$ and 16 years after surgery. 
More details about bone level data recorded in the first year after implant insertion are presented in a previous paper [26].

A long-cone parallel technique and an individualized film holder (Rinn bite film holder, Dentsply) with a polyvinyl siloxane bite registration were used to take radiographs.

A blinded clinician performed the measurements, by the use of a diaphanoscope and magnifying lens.

Interproximal bone level over the duration of the study was assessed from the implantabutment interface (considered as a reference point) to the most coronal bone at the mesial and distal aspects of each implant. BLC was measured as the difference between bone level at implant insertion (T0) and bone level at the follow-up appointment, expressing bone resorption with positive values.

\subsection{Soft Tissue Health Parameters}

Plaque control was made using a plaque gel detector, based on erythrosine (Butler GUM Red-Cote Liquid, Sunstar Americas, Inc., Chicago, IL, USA).

The O'Leary plaque index (PI) was assessed at four points for each implant (values from 0 to 4 for each implant).

Bleeding on probing (yes/no, $\mathrm{BOP}$ ) and probing depth (PD) were measured at four sites for each implant (mesial, distal, buccal, lingual).

PD was registered by the use of a Perio-Probe (Hawe Neos Dental, Bioggio, Switzerland).

$\mathrm{PI}$ and BOP were recorded annually for the first eight years, then at the 15- and 16-year follow-up. PD in Group 1 was recorded starting from the 6-year follow-up appointment and then at 7, 8, 15 and 16 years. In Group 2, PD was recorded at the first-year follow-up, and then at 4, 5, 6, 7, 8, 15 and 16 years after implant placement.

Technical and biological complications (such as the eventual presence of chipping of the veneering material, screw loosening and peri-implant suppuration) were also recorded.

\subsection{Prosthodontic Success Criteria}

The criteria established for prosthodontic success were the following:

- Absence of any modification of the original prostheses and its maintenance in situ;

- Patients' overall satisfaction with their prosthetic rehabilitation;

- Absence of mechanical and biologic complications.

\subsection{Implant Success Criteria}

Implant success was assessed according to Smith and Zarb's [40] criteria:

- The individual unattached implant is immobile when tested;

- No evidence of peri-implant radiolucency is present as assessed on an undistorted radiograph;

- Absence of peri-implant infection and the implant is capable to support a prosthodontic rehabilitation that is satisfactory both for the patient and the clinician;

- Mean vertical bone loss is less than $0.2 \mathrm{~mm}$ annually after physiologic remodeling during the first year of function.

\subsection{Statistical Analysis}

SPSS Statistics for iOS, Version 25.0 (IBM) program was used for statistical analysis of the collected data.

This analysis included an evaluation of the amount of bone resorption, as well as the parameters of soft tissue health.

OSS implants (control group) and FOSS implants (test group) were compared at the same time points with the Mann-Whitney U test.

Eventual overall (test and control group) differences over time were detected by nonparametric Wilcoxon test.

A $p$ value $\leq 0.05$ was considered statistically significant. A $95 \%$ confidence level was used. 
All the values in the descriptive analysis are expressed as mean, standard deviation and median.

The type of surface (test or control) was blind until the end of the statistical analysis.

The null hypothesis tested was that no significant differences exist between test and control implants in bone resorption and soft peri-implant tissue health parameters.

\section{Results}

Over the duration of the study, 6 patients dropped out: in Group 1, two patients with two implants each deceased seven years after implant placement, and a patient with 4 implants was untraceable after the 6-year follow-up. In Group 2, two patients moved away 6 years after implant insertion, while another did not attend the last appointment (6-year follow-up) because he lived far from the university division.

The mean follow-up period was 9.3 years (range: $5-16$ years) and only 3 patients with 2 implants each reached the 16-year follow-up (Table 1).

No implant failures occurred, and all implants were clinically stable and in function at the last follow-up appointment, resulting in an implant cumulative survival rate (iCSR) and an implant success rate of $100 \%$.

Only one technical complication was detected (one mandibular prostheses showed chipping of the veneering ceramic at the 15-year of follow-up), resulting in a prosthodontic cumulative survival rate (pCSR) of $100 \%$ and a prosthodontic success rate of $94.1 \%$.

All patients anecdotally reported to be satisfied with their implant rehabilitation.

Mean, median and standard deviation values of bone resorption (Table 2, Figure 3) and soft peri-implant tissue health parameters (Tables 3-5) in the two investigated groups are reported in the tables below.

Table 2. Interproximal BLC ( $\mathrm{mm}$ ) over time for OSS and FOSS implants (bone resorption was expressed in positive values). The $\left.{ }^{*}\right)$ refers to statistically significant values.

\begin{tabular}{|c|c|c|c|c|c|}
\hline \multirow[t]{2}{*}{$\begin{array}{c}\text { Follow-Up } \\
\text { Months/Years) }\end{array}$} & \multirow[t]{2}{*}{$\mathbf{N}^{\circ}$ of Patients } & \multirow[t]{2}{*}{$\mathbf{N}^{\circ}$ of Implants } & \multicolumn{3}{|c|}{ Mean (SD) } \\
\hline & & & Test (FOSS) & Control (OSS) & Global \\
\hline T0 & 18 & 42 & 0.00 & 0.00 & 0.00 \\
\hline 3 months & 18 & 42 & $0.4(0.5)[-0.1-0.9]$ & $1.0(0.7)$ [0.3-1.7] & $\begin{array}{c}0.7(0.7) *[0.0-1.4] \\
(p<0.001)\end{array}$ \\
\hline 6 months & 18 & 42 & $0.7(0.5)$ [0.2-1.2] & $\begin{array}{c}1.4 \\
(0.6)[0.8-2.0]\end{array}$ & $\begin{array}{c}1.0(0.6)^{*} \\
(p<0.001)[0.4-1.6]\end{array}$ \\
\hline 1 year & 18 & 42 & $\begin{array}{c}0.8 \\
(0.6)^{*} \\
(p=0.002)^{[0.2-1.4]}\end{array}$ & $1.4(0.6)[0.8-2.0]$ & $\begin{array}{c}1.1 \\
(0.6)[0.5-1.7]\end{array}$ \\
\hline 5 years & 18 & 42 & $\begin{array}{c}1.4(0.5)^{*} \\
(p=0.011)[0.9-2.9]\end{array}$ & $1.9(0.7)[1.2-2.6]$ & $\begin{array}{c}1.6(0.7) * \\
p<0.001[0.9-2.3]\end{array}$ \\
\hline 6 years & 15 & 36 & $\begin{array}{c}1.4(0.5)^{*} \\
(p=0.008)[0.9-1.9]\end{array}$ & $\begin{array}{l}2.0(0.7) \\
{[1.3-2.7]}\end{array}$ & $\begin{array}{c}1.7(0.7)^{*} \\
(p=0.024)[1.0-2.4]\end{array}$ \\
\hline 7 years & 12 & 28 & $\begin{array}{c}1.5 \\
(0.6) * \\
(p=0.027) \\
{[0.9-2.1]}\end{array}$ & $\begin{array}{l}2.2(0.7) \\
{[1.5-2.9]}\end{array}$ & $\begin{array}{c}1.8 \\
(0.7)[1.1-3.5]\end{array}$ \\
\hline 8 years & 9 & 22 & $\begin{array}{c}1.5 \\
(0.6) \\
{[0.9-2.1]}\end{array}$ & (0.7) $\frac{2.2}{[1.5-2.9]}$ & $\begin{array}{c}1.8 \\
(0.7))^{*} \\
(p=0.11)[1.1-3.5]\end{array}$ \\
\hline 15 years & 5 & 12 & $\begin{array}{c}1.4 \\
(0.4) \\
{[1.0-1.8]}\end{array}$ & $1.9(0.4)[1.5-2.3]$ & $\begin{array}{c}1.7(0.5)^{*} \\
(p=0.27)[1.2-2.3]\end{array}$ \\
\hline 16 years & 3 & 6 & $\begin{array}{c}1.6 \\
(0.8) \\
{[0.8-2.4]}\end{array}$ & $\begin{array}{l}1.8(0.6) \\
{[1.2-2.4]}\end{array}$ & $1.7(0.7)$ [1.0-2.4] \\
\hline
\end{tabular}




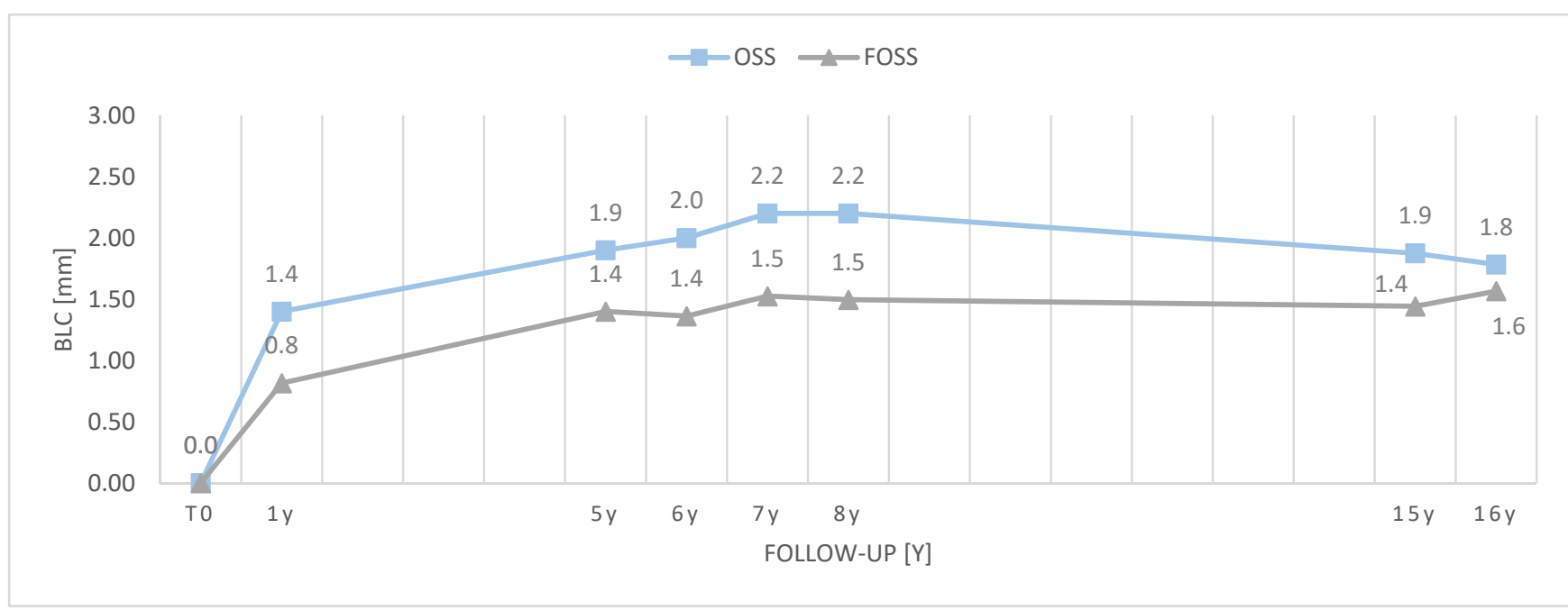

Figure 3. Interproximal bone level change (BLC, $\mathrm{mm}$ ) over time for implant type; $\mathrm{y}=$ years.

Table 3. Values of PD (mm) over time for control (OSS) and test (FOSS) implants.

\begin{tabular}{|c|c|c|c|c|c|c|}
\hline \multirow{2}{*}{$\begin{array}{l}\text { Follow-Up } \\
\text { (Years) }\end{array}$} & \multirow[t]{2}{*}{$\mathbf{N}^{\circ}$ of Patients } & \multicolumn{2}{|c|}{$\mathbf{N}^{\circ}$ of Implants } & \multicolumn{3}{|c|}{ Mean (SD) } \\
\hline & & Test (FOSS) & Control (OSS) & Test (FOSS) & Control (OSS) & Global \\
\hline $\mathrm{T} 1$ & 10 & 11 & 11 & $\begin{array}{c}3.2 \\
(0.9)[2.3-3.1]\end{array}$ & $\begin{array}{c}3.0 \\
(0.6)[2.4-3.6]\end{array}$ & $\begin{array}{c}3.1 \\
(0.7)[2.4-3.8]\end{array}$ \\
\hline $\mathrm{T} 4$ & 10 & 11 & 11 & $\begin{array}{c}2.9 \\
\text { (1.1) }[1.8-4.0]\end{array}$ & $\begin{array}{c}2.8 \\
(0.9)[1.9-3.7]\end{array}$ & $\begin{array}{c}2.8 \\
(1.0)[1.8-3.8]\end{array}$ \\
\hline $\mathrm{T} 5$ & 10 & 11 & 11 & $\begin{array}{c}3.2 \\
(1.3)[0.9-4.5]\end{array}$ & $\begin{array}{c}3.1 \\
(1.3)[1.8-4.4]\end{array}$ & $\begin{array}{c}3.1 \\
(1.3)[1.8-4.4]\end{array}$ \\
\hline $\mathrm{T} 6$ & 16 & 19 & 19 & $\begin{array}{c}2.6 \\
(0.9)[1.7-3.5]\end{array}$ & $\begin{array}{c}2.6 \\
(0.9)[1.7-3.5]\end{array}$ & $\begin{array}{c}2.6 \\
(0.9)[1.7-3.5]\end{array}$ \\
\hline $\mathrm{T} 7$ & 12 & 19 & 19 & $\begin{array}{c}2.8 \\
(0.8)[2.0-3.6]\end{array}$ & $\begin{array}{c}2.7 \\
(0.7)(2.0-3.4)\end{array}$ & $\begin{array}{c}2.8 \\
(0.8)[2.0-3.6]\end{array}$ \\
\hline $\mathrm{T} 8$ & 9 & 11 & 11 & $\begin{array}{c}2.8 \\
(0.7)[2.1-3.5]\end{array}$ & $\begin{array}{c}2.9 \\
(0.7)[2.1-3.5]\end{array}$ & $\begin{array}{c}2.8 \\
(0.7)[2.1-3.5]\end{array}$ \\
\hline $\mathrm{T} 15$ & 5 & 6 & 6 & $\begin{array}{c}2.7 \\
(0.9)[1.8-3.6]\end{array}$ & $\begin{array}{c}2.9 \\
(0.5)[2.7-3.4]\end{array}$ & $\begin{array}{c}2.8 \\
(0.7)[2.1-3.5]\end{array}$ \\
\hline T16 & 3 & 3 & 3 & $\begin{array}{c}2.7 \\
(0.6)[2.1-3.2]\end{array}$ & $\begin{array}{c}3.2 \\
(0.7)[2.5-3.9]\end{array}$ & $\begin{array}{c}3.0 \\
(0.6)[2.4-3.6]\end{array}$ \\
\hline
\end{tabular}

When the implants were inserted, the implant shoulder was at the level of bone crest in all the clinical cases, so the authors measured interproximal bone resorption starting from the implant-abutment interface.

Overall mean BLC values varied significantly during the first 3 months $(p<0.001)$ after implant insertion; between the 3- and 6-month follow-up appointment $(p<0.001)$; between the 6-month and the 1-year follow-up $(p=0.024)$; between the first and the fifth year $(p<0.001)$; between the 6- and 8-year follow-up $(p=0.011)$; and between the 8- and 15-year follow-up $(p=0.027)$.

No statistically significant differences were found between test and control implants for soft tissue health parameters (PI, BOP, and PD), the null hypothesis was therefore only partly rejected.

Most of the patients did not show BOP, and no patient presented suppuration. 
Table 4. Values of BOP over time for OSS and FOSS implants.

\begin{tabular}{|c|c|c|c|c|c|c|}
\hline \multirow[t]{2}{*}{$\begin{array}{l}\text { Follow-Up } \\
\quad \text { (Years) }\end{array}$} & \multirow[t]{2}{*}{$\mathbf{N}^{\circ}$ of Patients } & \multicolumn{2}{|c|}{$\mathbf{N}^{\circ}$ of Implants } & \multicolumn{3}{|c|}{ Mean (SD) } \\
\hline & & Test (FOSS) & Control (OSS) & Test (FOSS) & Control (OSS) & Global \\
\hline $\mathrm{T} 1$ & 18 & 21 & 21 & $\begin{array}{c}1.0 \\
(1.2)[-0.2-2.2]\end{array}$ & $\begin{array}{c}0.8 \\
(1.2)[-0.4-2.0]\end{array}$ & $\begin{array}{c}0.9 \\
(1.2)[-0.3-2.1]\end{array}$ \\
\hline $\mathrm{T} 2$ & 18 & 21 & 21 & $\begin{array}{c}1.0 \\
(1.0)[0.0-2.0]\end{array}$ & $\begin{array}{c}0.8 \\
(1.0)[-0.2-1.8]\end{array}$ & $\begin{array}{c}0.9 \\
(0.9)[0.0-1.8]\end{array}$ \\
\hline $\mathrm{T} 3$ & 18 & 21 & 21 & $\begin{array}{c}1.1 \\
(1.1)[0.0-2.2]\end{array}$ & $\begin{array}{c}1.1 \\
(1.1)[0.0-2.2]\end{array}$ & $\begin{array}{c}1.1 \\
(1.1)[0.0-2.2]\end{array}$ \\
\hline $\mathrm{T} 4$ & 18 & 21 & 21 & $\begin{array}{c}1.3 \\
(1.0)[-0.2-2.3]\end{array}$ & $\begin{array}{c}1.2 \\
(1.0)[0.2-2.2]\end{array}$ & $\begin{array}{c}1.3 \\
(1.0)[-0.2-2.3]\end{array}$ \\
\hline T5 & 18 & 21 & 21 & $\begin{array}{c}2.0 \\
(1.3)[0.7-3.3]\end{array}$ & $\begin{array}{c}1.6 \\
(1.2)[0.4-3.9]\end{array}$ & $\begin{array}{c}1.8 \\
(1.3)[0.5-3.1]\end{array}$ \\
\hline $\mathrm{T} 6$ & 15 & 18 & 18 & $\begin{array}{c}1.4 \\
(1.2)[0.2-2.6]\end{array}$ & $\begin{array}{c}1.2 \\
(1.0)[0.2-2.2]\end{array}$ & $\begin{array}{c}1.3 \\
(1.1)[0.2-2.4]\end{array}$ \\
\hline $\mathrm{T} 7$ & 12 & 14 & 14 & $\begin{array}{c}1.1 \\
(1.1)[0.0-2.2]\end{array}$ & $\begin{array}{c}1.0 \\
(0.9)[1.1-1.9]\end{array}$ & $\begin{array}{c}1.0 \\
(1.0)[0.0-2.0]\end{array}$ \\
\hline $\mathrm{T} 8$ & 9 & 11 & 11 & $\begin{array}{c}1.1 \\
(1.4)[-0.3-2.5]\end{array}$ & $\begin{array}{c}1.2 \\
(1.5)[-0.3-2.7]\end{array}$ & $\begin{array}{c}1.1 \\
(1.4)[-0.3-2.5]\end{array}$ \\
\hline $\mathrm{T} 15$ & 5 & 6 & 6 & $\begin{array}{c}0.9 \\
(1.0)[-0.1-1.9]\end{array}$ & $\begin{array}{c}1.0 \\
(0.9)[0.1-1.9]\end{array}$ & $\begin{array}{c}0.9 \\
(0.9)[0.8-1.8]\end{array}$ \\
\hline $\mathrm{T} 16$ & 3 & 3 & 3 & $\begin{array}{c}1.0 \\
(1.7)[-0.7-2.7]\end{array}$ & $\begin{array}{c}1.7 \\
(1.5)[0.2-2.3]\end{array}$ & $\begin{array}{c}1.3 \\
(1.5)[-0.2-2.8]\end{array}$ \\
\hline
\end{tabular}

Table 5. Values of PI over time for OSS and FOSS implants.

\begin{tabular}{|c|c|c|c|c|c|c|}
\hline \multirow{2}{*}{$\begin{array}{c}\text { Follow-Up } \\
\text { (Years) }\end{array}$} & \multirow[t]{2}{*}{$\mathbf{N}^{\circ}$ of Patients } & \multicolumn{2}{|c|}{$\mathbf{N}^{\circ}$ of Implants } & \multicolumn{3}{|c|}{ Mean (SD) } \\
\hline & & Test (FOSS) & Control (OSS) & Test (FOSS) & Control (OSS) & Global \\
\hline $\mathrm{T} 1$ & 18 & 21 & 21 & $\begin{array}{c}1.9 \\
(1.2)[0.7-3.1]\end{array}$ & $\begin{array}{c}1.5 \\
(1.1)[0.4-2.6]\end{array}$ & $\begin{array}{c}1.7 \\
(1.1)[0.6-2.8]\end{array}$ \\
\hline $\mathrm{T} 2$ & 18 & 21 & 21 & $\begin{array}{c}1.8 \\
(1.0)[0.8-2.8]\end{array}$ & $\begin{array}{c}1.5 \\
(0.8)[0.7-2.3]\end{array}$ & $\begin{array}{c}1.6 \\
(0.9)[0.7-2.5]\end{array}$ \\
\hline $\mathrm{T} 3$ & 18 & 21 & 21 & $\begin{array}{c}1.8 \\
(1.1)[0.7-2.9]\end{array}$ & $\begin{array}{c}2.1 \\
(1.2)[0.9-3.3]\end{array}$ & $\begin{array}{c}1.9 \\
(1.1)[0.8-3.0]\end{array}$ \\
\hline $\mathrm{T} 4$ & 18 & 21 & 21 & $\begin{array}{c}2.1 \\
(1.2)[0,9-3.3]\end{array}$ & $\begin{array}{c}1.9 \\
(1.0)[0.9-2.9]\end{array}$ & $\begin{array}{c}2.0 \\
(1.1)[0.9-3.1]\end{array}$ \\
\hline $\mathrm{T} 5$ & 18 & 21 & 21 & $\begin{array}{c}2.1 \\
(1.5)[0.6-3.6]\end{array}$ & $\begin{array}{c}2.3 \\
(1.6)[0.7-3.9]\end{array}$ & $\begin{array}{c}2.2 \\
(1.5)[0.7-3.7]\end{array}$ \\
\hline T6 & 15 & 18 & 18 & $\begin{array}{c}1.9 \\
(1.7)[0.2-3.6]\end{array}$ & $\begin{array}{c}1.9 \\
(1.6)[0.3-3.5]\end{array}$ & $\begin{array}{c}1.9 \\
(1.6)[0.3-3.5]\end{array}$ \\
\hline $\mathrm{T} 7$ & 12 & 14 & 14 & $\begin{array}{c}1.3 \\
(1.2)[0.1-2.5]\end{array}$ & $\begin{array}{c}1.3 \\
(1.1)[0.2-2.4]\end{array}$ & $\begin{array}{c}1.3 \\
(1.1)[0.2-2.4]\end{array}$ \\
\hline $\mathrm{T} 8$ & 9 & 11 & 11 & $\begin{array}{c}1.0 \\
(1.5)[-0.5-2.5]\end{array}$ & $\begin{array}{c}1.5 \\
(1.3)[0.2-2.8]\end{array}$ & $\begin{array}{c}1.3 \\
(1.4)[-0.1-2.7]\end{array}$ \\
\hline $\mathrm{T} 15$ & 5 & 6 & 6 & $\begin{array}{c}1.5 \\
(1.4)[0.1-2.9]\end{array}$ & $\begin{array}{c}1.7 \\
(1.5)[0.2-3.2]\end{array}$ & $\begin{array}{c}1.6 \\
(1.4)[0.2-3.0]\end{array}$ \\
\hline T16 & 3 & 3 & 3 & $\begin{array}{c}1.0 \\
(1.0)[0.0-2.0]\end{array}$ & $\begin{array}{c}1.0 \\
(1.0)[0.0-2.0]\end{array}$ & $\begin{array}{c}1.0 \\
(0.9)[0.1-1.9]\end{array}$ \\
\hline
\end{tabular}


The differences in BLC between the two differently surfaced implants were statistically significant only at the first-year follow-up $(p=0.002)$, and then at the 5- $(p=0.011)$, 6- $(p=0.008)$ and 7-year follow-up appointment. $(p=0.027)$. No statistically significant differences in BLC were found at the subsequent follow-ups.

\section{Discussion}

The aim of the present prospective clinical trial, with an up to 16-year follow-up, was to investigate the impact of titanium implants with different surface treatments on peri-implant hard and soft tissues. The findings of the study showed that acid-etched implant surfaces reduced peri-implant bone resorption in the initial phase of healing, while it did not seem to have a significant effect at subsequent time points. In addition, no significant differences were found in soft tissue health parameters next to the two differently surfaced implants.

The present study was the continuation of previous studies of the same team of authors, reported in already published manuscripts [26-29]. The first published paper [26] compared the two types of implants (Osseotite and Full Osseotite) in a sample of eight patients (Group 1). The authors monitored for 12 months peri-implant bone resorption over time and the health of soft peri-implant tissues, recording bleeding on probing score (BOP) and making a histologic analysis on bioptic samples from peri-implant mucosa. A second manuscript [27] reported results of the previous study at the 6-year follow-up, also reporting peri-implant depth (PD).

Menini et al. (2017) [28] reported data of a different cohort of 10 patients (Group 2) and besides bone level, PI, BOP, and PD, the investigation included a mini-invasive sample of soft tissue for miRNA microarray analysis. A subsequent paper [29] reported results of this second cohort of patient at the 5-year follow-up.

According to preliminary results of previous papers $[27,29]$ on the same pool of patients, DAE (test) surfaces induced greater plaque accumulation, however they showed lower peri-implant bone resorption.

In both groups of implants, the greatest bone loss occurred during the first year after implant placement (Figure 3). This is consistent with the physiological bone remodeling that takes place after the surgical trauma and in response to occlusal forces after prosthesis delivery [41].

At the first-year follow-up, bone resorption around FOSS implants was statistically lower than in the control group (0.80 vs. $1.39 \mathrm{~mm} ; p=0.002)$. Subsequently bone level went through a steady state, in fact implant surface mainly influenced bone level changes only in the first phase of healing after implant insertion. Once osseointegration and periimplant bone remodeling after prosthesis delivery was complete, the type of surface was less relevant.

After the first year of healing, lower bone level changes occurred in both types of implants. A significant overall increase in bone resorption was also found between the 6-year and the 8-year follow-up appointment (mean: 1.65 vs. $1.82 \mathrm{~mm} ; p=0.011$ ). However, it is worth specifying that while fifteen patients were available at the 6-year follow-up appointment, only nine reached the 8-year follow-up and only three reached the 16-year follow-up. This probably affected the results. Due to this selection bias, mean bone loss was smaller at the 15- and 16-year follow-up appointments compared to previous time points.

No differences in PI were detected between test and control sites from the 1-year follow-up appointment on. The higher PI recorded in the test group in the first months of healing was due to the presence of the DAE surfaced healing abutments. The healing abutments were removed after 21 weeks from surgery, for the insertion of provisional prostheses. Therefore, from that moment on, further changes in PI could be mainly referred to the prosthesis veneering material and the metal prosthesis structure which were exposed into the oral environment.

Mean PI did not significantly increase over time, despite the mean age of patients increased and the majority of patients missed some of their usual professional oral hygiene 
appointments during the pandemic from Coronavirus 19 in 2020 . This outcome can be explained by a good compliance with home oral care recommendations, and also by local factors such as the presence of a sufficient keratinized mucosa [42-44], although the presence of keratinized mucosa was not specifically investigated in the present research.

PI was considered satisfactory, even in those prostheses provided with resin composite used as aesthetic veneering material, which is known to be more plaque retentive than ceramic [45]. No statistically significant differences in bone resorption were found between implants rehabilitated with ceramic vs. composite resin veneering material as well.

Despite the initial higher plaque accumulation around FOSS implants, the type of implant surface did not affect soft tissues health. In fact, BOP was absent at the majority of the implant sites and mean PD was within normal limits, with the greatest mean global PD value being $3.14 \mathrm{~mm}$ at the 5-year follow-up appointment, without statistically significant differences between the two implant types.

These outcomes are consistent with the histological outcomes reported in the previously published study [26].

As described in a previous paper [2], in Group 2, mini-invasive samples of soft tissue surrounding implants were taken in order to evaluate microRNA (miRNA) expression at the implant sites by microarray analysis. Ninety-six miRNAs were found to be differently expressed next to FOSS and OSS implants indicating that peri-implant tissue reacts differently to the insertion of different implant types. In addition, peri-implant soft tissue inflammation appeared to be more related to miRNA expression than to plaque accumulation or to implant surface (machined vs. DAE). In particular, specific miRNA expression profiles were found that seemed to protect implant sites from inflammation (BOP) and bone resorption, irrespective of plaque accumulation, suggesting that individual host characteristics play a pivotal role in the behavior of peri-implant tissues.

Many studies [46-48] suggested that rough surfaces promote osseointegration compared with smooth surfaces, thanks to their better osteogenic potential. Clinical studies showed that rough surfaces, when compared to turned/machined surfaces, could provide greater BIC and increased removal torque values [47]. This could be translated in shorter healing times from implant insertion to restoration. According to Davies $[49,50]$ the implant surface design plays an important role in peri-implant endosseous healing. In particular, microtopographically complex surfaces could potentiate the activation of platelets, which will produce cytokines and growth factors modulating osseointegration. These surfaces would also promote osteoconduction by both increasing the available surface area for fibrin attachment and increasing the retention of the transient fibrin-based structural matrix of the blood clot through which osteogenic cells must migrate to reach the implant surface after implant insertion. It must be underlined that Davies' manuscripts focused on implants with dual acid-etched (DAE) surfaces compared with traditional machined surfaces such as in the study herein reported.

In addition, another study supported that titanium surface topography and chemistry have a significant effect on platelet activation and chemokine release [51].

The implant surface also plays a role in the modulation of gene expression encoding for osteogenic activities on the osteoblasts [7]. However, it is still not clear which combination of different surface treatments induce a specific biological response and provide the best clinical behaviour [52].

Some authors found that implant with rough surfaces had greater success rates [53], while, in contrast, in a recent systematic review Doornewaard et al. [54] have reported significantly higher bone loss next to moderately rough and rough compared to minimally rough (i.e., machined or DAE) surfaces. However, the heterogeneity of the studies retrieved and the multifactorial etiology of bone loss lead the authors concluding that "the impact of surface roughness alone seems rather limited and of minimal clinical importance".

Surface roughness also seems to have a positive effect especially in poor quality bone, even if this issue has not yet been well established [55]. 
Finally, there is still limited evidence of a possible effect of implant surfaces on the progression of peri-implantitis [11]. It must also be considered that the wide variety of different macro- and micro-design of dental implants might make difficult comparing the outcomes of different studies and draw sound conclusions.

According to a systematic review [54], which is also consistent with the results of the present research, when evaluating long-term outcomes, the clinical impact of implant surface alone might play a minor role, supporting the concept of a multifactorial etiology of bone loss. Peri-implant bone resorption can be influenced by several other factors, different from implant surface characteristics, which may make it difficult to interpret clinical outcomes. For instance, the implant receiving site can play a significant role. A systematic review by Berglundh et al. [56] has revealed that implant failure happened more often in the maxilla than in the mandible, and in posterior regions than in anterior areas. The authors related the failure to the quality of bone in the different sites. However, in the present study only two implants out of forty-two were placed in anterior sites, and for this reason a statistical analysis to detect possible differences between anterior and posterior areas was not performed.

Prosthodontic aspects may also affect peri-implant bone maintenance and the occurrence of biological and technical complications. From a biomechanical point of view, implant-supported splinted crowns, provide a better load distribution, compared to single crowns, favoring a reduction of the stress transmitted to the implant-abutment and the cortical bone tissue [57].

In the present study, implant splinting could have helped in controlling occlusal load and keeping peri-implant bone remodeling within physiological limits. However, it is impossible to establish if further differences would have been present in bone level change between OSS and FOSS implants, in case of non-splinted implant-supported crowns. The topic is controversial and in a RTC with a 10-year follow-up by Vigolo et al., no significant differences in peri-implant bone resorption were detected comparing splinted to nonsplinted implants [58].

The passive fit of the prosthesis framework may also have a role in clinical outcomes, although this has not been conclusively demonstrated in clinical trials. A recent systematic review by Pan et al. has concluded that the passivity of implant-supported fixed prostheses appeared related to the induced strain/stress (as demonstrated in in vitro studies), but not to the clinical complications [59].

In addition to those already mentioned, also other co-variables such as systemic pathologic conditions, or the history of periodontitis and the compliance to supportive therapy may affect dental implants' clinical outcomes. According to a recent systematic review and metanalysis [60], the history of periodontitis is a negative indicator for implant survival even under regular supportive post-implant treatment coverage in rough-surfaced implants and is also related with more radiologic marginal bone loss, pocket depth, and bleeding on probing. However, using implants with a machined surface, no statistically significant difference in survival rate was found between patients with and without a history of periodontal disease. A comparison of the clinical outcomes between patients with and without a history of periodontal disease was not possible in the present study, since a positive anamnesis for periodontitis was one of the exclusion criteria.

Patients affected by uncontrolled diabetes mellitus and under intravenous bisphosphonate medication were also excluded. These two systemic conditions have a possible role in peri-implant tissue healing after implant insertion and in bone maintenance over time, although the very recent consensus report of the Oral Reconstruction Foundation [61] concluded that diabetes mellitus and low-dose oral bisphosphonate treatment for osteoporosis are not risk factors for implant survival in the short term.

The split-mouth design of the present investigation helped reducing the effect of the numerous confounding factors mentioned above. No prospective clinical studies with a split-mouth design are available in the literature investigating implant surfaces and none 
with a long-term follow-up. Clinical trials with a split-mouth design and a long-term follow-up can provide sound indications for clinical practice.

The main limitation of the present research is the small sample size and the high number of dropouts (six out of eighteen patients at the 7-year follow-up), which could have significantly impacted the outcomes and possibly introduced a selection bias. The high number of dropouts at the last follow-up appointment might also be partly attributed to COVID pandemic that deterred some patients from attendance to routine follow-up appointments. On the other side, one of the strengths of this study design is that it is one of the few clinical investigations available in the literature comparing two dental implants that are identical except for their surface. In fact, the only difference between the two implant types was the surface treatment in their coronal portion, and both types of implants appeared radiographically identical. As a consequence, all the possible differences between the two groups are attributable only to the different type of surface.

In conclusion, the outcomes of the present prospective clinical trial with an up to 16-year follow-up up showed that dual acid-etched titanium surfaces induced less periimplant bone loss during the first year after implant insertion compared to machined surfaces in partial delayed loading rehabilitations. However, bone resorption over the following years was not affected by the type of surface.

In addition, implant surface characteristics had no effects on soft peri-implant tissues health parameters, supporting that dual acid-etched titanium surfaces favor bone maintenance over time and their roughness is not to be considered a risk factor for peri-implant disease.

Further investigations with a larger sample size are needed to clarify the long-term impact of titanium surface characteristics on dental implant clinical outcomes.

Author Contributions: Conceptualization, M.M. and F.D.; methodology, D.B.; software, N.D.T.; validation, E.P., P.P. (Paolo Pera) and F.P.; formal analysis, F.B. and N.D.T.; investigation, D.B. and F.D.; resources, P.P. (Paolo Pera); data curation, P.P. (Paolo Pesce); writing—original draft preparation, M.M., F.D. and E.P.; writing-review and editing, M.M. and F.D.; visualization, P.P. (Paolo Pesce); supervision, M.M.; project administration, P.P. (Paolo Pera) and M.M.; funding acquisition, M.M. and P.P. (Paolo Pesce). All authors have read and agreed to the published version of the manuscript.

Funding: This research received no external funding.

Institutional Review Board Statement: The study was conducted according to the guidelines of the Declaration of Helsinki, and approved by the Institutional Review Board of University of Genoa (protocol code 21084).

Informed Consent Statement: Informed consent was obtained from all subjects involved in the study.

Conflicts of Interest: The authors declare no conflict of interest.

\section{References}

1. Novaes, A.B., Jr.; de Souza, S.L.; de Barros, R.R.; Pereira, K.K.; Iezzi, G.; Piattelli, A. Influence of implant surfaces on osseointegration. Braz Dent. J. 2010, 21, 471-481. [CrossRef] [PubMed]

2. Menini, M.; Pera, F.; Bagnasco, F.; Delucchi, F.; Morganti, E.; Canullo, L.; Pesce, P. Morphological and chemical characterization of titanium and zirconia dental implants with different macro- and micro-structure. Appl. Sci. 2020, 10, 7520. [CrossRef]

3. Kligman, S.; Ren, Z.; Chung, C.H.; Perillo, M.A.; Chang, Y.C.; Koo, H.; Zheng, Z.; Li, C. The Impact of Dental Implant Surface Modifications on Osseointegration and Biofilm Formation. J. Clin. Med. 2021, 10, 1641. [CrossRef]

4. Conserva, E.; Lanuti, A.; Menini, M. Cell behavior related to implant surfaces with different microstructure and chemical composition: An in vitro analysis. Int. J. Oral Maxillofac. Implant. 2010, 25, 1099-1107.

5. Conserva, E.; Menini, M.; Ravera, G.; Pera, P. The role of surface implant treatments on the biological behavior of SaOS-2 osteoblast-like cells. An in vitro comparative study. Clin. Oral Implant. Res. 2013, 24, 880-889. [CrossRef] [PubMed]

6. Menini, M.; Delucchi, F.; Bagnasco, F.; Pera, F.; Di Tullio, N.; Pesce, P. Analysis of the Subgingival Microbiota in Implant-Supported Full-Arch Rehabilitations. Dent. J. 2020, 8, 104. [CrossRef] [PubMed]

7. Baldi, D.; Longobardi, M.G.; Cartiglia, C.; La Maestra, S.; Pulliero, A.; Bonica, P.; Micale, R.; Menini, M.; Pera, P.; Izzotti, A. Dental Implants Osteogenic Properties Evaluated by cDNA Microarrays. Implant. Dent. 2011, 20, 299-304. [CrossRef]

8. Menini, M.; Delucchi, F.; Baldi, D.; Pera, F.; Bagnasco, F.; Pesce, P. Macrophagic Inflammatory Response Next to Dental Implants with Different Macro- and Micro-Structure: An In Vitro Study. Appl. Sci. 2021, 11, 5324. [CrossRef] 
9. Albrektsson, T.; Wennerberg, A. Oral implant surfaces: Part 1-review focusing on topographic and chemical properties of different surfaces and in vivo responses to them. Int. J. Prosthodont. 2004, 17, 536-543. [PubMed]

10. Folkman, M.; Becker, A.; Meinster, I.; Masri, M.; Ormianer, Z. Comparison of bone-to-implant contact and bone volume around implants placed with or without site preparation: A histomorphometric study in rabbits. Sci. Rep. 2020, 10, 12446. [CrossRef]

11. Bosshardt, D.D.; Chappuis, V.; Buser, D. Osseointegration of titanium, titanium alloy and zirconia dental implants: Current knowledge and open questions. Periodontol. 2000 2017, 73, 22-40. [CrossRef] [PubMed]

12. Cooper, L.F. A role for surface topography in creating and maintaining bone at titanium endosseous implants. J. Prosthet Dent. 2000, 84, 522-534. [CrossRef] [PubMed]

13. Lang, N.P.; Jepsen, S. Implant surfaces and design. Clin. Oral Implant. Res. 2009, 20, 228-231. [CrossRef] [PubMed]

14. Dong, H.; Liu, H.; Zhou, N.; Li, Q.; Yang, G.; Chen, L.; Mou, Y. Surface Modified Techniques and Emerging Functional Coating of Dental Implants. Coatings 2020, 10, 1012. [CrossRef]

15. Pesce, P.; Menini, M.; Santori, G.; Giovanni, E.; Bagnasco, F.; Canullo, L. Photo and Plasma Activation of Dental Implant Titanium Surfaces. A Systematic Review with Meta-Analysis of Pre-Clinical Studies. J. Clin. Med. 2020, 9, 2817. [CrossRef] [PubMed]

16. Mangano, F.G.; Pires, J.T.; Shibli, J.A.; Mijiritsk, E.; Iezzi, G.; Piattelli, A.; Mangano, C. Early Bone Response to Dual Acid-Etched and Machined Dental Implants Placed in the Posterior Maxilla: A Histologic and Histomorphometric Human Study. Implant. Dent. 2017, 26, 24-29. [CrossRef] [PubMed]

17. Annunziata, M.; Rizzo, A.; Leone, C.; Mangano, C. Bacterial adhesion to direct laser metal formed and mildly acid-etched implant surfaces. Surf. Coat. Technol. 2017, 328, 390-397. [CrossRef]

18. Quirynen, M.; van der Mei, H.C.; Bollen, C.M.; Schotte, A.; Marechal, M.; Doornbusch, G.I.; Naert, I.; Busscher, H.J.; van Steenberghe, D. An in vivo study of the Influence of the surface roughness of implants on the microbiology of supra- and subgingival plaque. J. Dent. Res. 1993, 72, 1304-1309. [CrossRef] [PubMed]

19. Bollen, C.M.; Papaioanno, W.; Van Eldere, J.; Schepers, E.; Quirynen, M.; van Steenberghe, D. The influence of abutment surface roughness on plaque accumulation and peri-implant mucositis. Clin. Oral Implant. Res. 1996, 7, 201-211. [CrossRef]

20. Lindhe, J.; Meyle, J. Peri-implant diseases: Consensus Report of the Sixth European Workshop on Periodontology. J. Clin. Periodotol. 2008, 35, 282-285. [CrossRef]

21. Beutner, R.; Michael, J.; Schwenzer, B.; Scharnweber, D. Biological nano-functionalization of titanium-based biomaterial surfaces: A flexible toolbox. J. R Soc. Interface 2010, 7, 93-105. [CrossRef] [PubMed]

22. Lutz, R.; Srour, S.; Nonhoff, J.; Weisel, T.; Damien, C.J.; Schlegel, K.A. Biofunctionalization of titanium implants with a biomimetic active peptide (P-15) promotes early osseointegration. Clin. Oral Implants Res. 2010, 21, 726-734. [CrossRef] [PubMed]

23. Renvert, S.; Polyzois, I.; Claffey, N. How do implant surface characteristics influence peri-implant disease? J. Clin. Periodontol. 2011, 38, 214-222. [CrossRef] [PubMed]

24. Menini, M.; Setti, P.; Pera, P.; Pera, F.; Pesce, P. Peri-implant tissue health and bone resorption in immediately loaded, implantsupported full-arch prostheses. Int. J. Prosthodont. 2018, 31, 327-333. [CrossRef] [PubMed]

25. Pesce, P.; Menini, M.; Tealdo, T.; Bevilacqua, M.; Pera, F.; Pera, P. Peri-implantitis: A systematic review of recently published papers. Int. J. Prosthodont. 2014, 27, 15-25. [CrossRef] [PubMed]

26. Baldi, D.; Menini, M.; Pera, F.; Ravera, G.; Pera, P. Plaque accumulation on exposed titanium surfaces and peri-implant tissue behavior. A preliminary 1-year clinical study. Int. J. Prosthodont. 2009, 22, 447-455. [PubMed]

27. Menini, M.; Dellepiane, E.; Chvartszaid, D.; Baldi, D.; Schiavetti, I.; Pera, P. Influence of Different Surface Characteristics on Peri-implant Tissue Behavior: A Six-Year Prospective Report. Int. J. Prosthodont. 2015, 28, 389-395. [CrossRef]

28. Menini, M.; Dellepiane, E.; Baldi, D.; Longobardi, M.G.; Pera, P.; Izzotti, A. Microarray expression in peri-implant tissue next to different titanium implant surfaces predicts clinical outcomes: A split-mouth study. Clin. Oral Implant. Res. 2017, 28, 121-134. [CrossRef]

29. Menini, M.; Pesce, P.; Baldi, D.; Coronel Vargas, G.; Pera, P.; Izzotti, A. Prediction of Titanium Implant Success by Analysis of microRNA Expression in Peri-Implant Tissue. A 5-Year Follow-Up Study. J. Clin. Med. 2019, 8, 888. [CrossRef] [PubMed]

30. De Angelis, N.; Kassim, Z.H.; Baharuddin, I.H.; Parker, S.; Colombo, E.; Amaroli, A.; Signore, A. Ten-Year Results of a Prospective Cohort Study on Acid-Etched and Airborne Particle-Abraded Implant Surfaces: A Comparative Study. Int. J. Periodontics Restor. Dent. 2020, 40, 189-196. [CrossRef] [PubMed]

31. Buser, D.; Janner, S.F.; Wittneben, J.G.; Brägger, U.; Ramseier, C.A.; Salvi, G.E. 10-year survival and success rates of 511 titanium implants with a sandblasted and acid-etched surface: A retrospective study in 303 partially edentulous patients. Clin. Implant. Dent. Relat Res. 2012, 14, 839-851. [CrossRef] [PubMed]

32. Llewellyn-Bennett, R.; Edwards, D.; Roberts, N.; Hainsworth, A.H.; Bulbulia, R.; Bowman, L. Post-trial follow-up methodology in large randomised controlled trials: A systematic review. Trials 2018, 19, 298. [CrossRef] [PubMed]

33. Hwang, D.; Wang, H.L. Medical contraindications to implant therapy: Part II: Relative contraindications. Implant. Dent. 2007, 16, 13-23. [CrossRef] [PubMed]

34. Bornstein, M.M.; Cionca, N.; Mombelli, A. Systemic conditions and treatments as risks for implant therapy. Int. J. Oral Maxillofac Implant. 2009, 24, 12-27.

35. Von Elm, E.; Altman, D.G.; Egger, M.; Pocock, S.J.; Gøtzsche, P.C.; Vandenbroucke, J.P. STROBE Initiative. The Strengthening the Reporting of Observational Studies in Epidemiology (STROBE) statement: Guidelines for reporting observational studies. J. Clin. Epidemiol. 2008, 61, 344-349. 
36. Spray, J.R.; Black, C.G.; Morris, H.F.; Ochi, S. The influence of bone thickness on facial marginal bone response: Stage 1 placement through stage 2 uncovering. Ann. Periodontol. 2000, 5, 119-128. [CrossRef]

37. Tarnow, D.P.; Cho, S.C.; Wallace, S.S. The effect of inter-implant distance on the height of inter-implant bone crest. J. Periodontol. 2000, 71, 546-549. [CrossRef] [PubMed]

38. Esposito, M.; Ekestubbe, A.; Grondahl, K. Radiological evaluation of marginal bone loss at tooth surfaces facing single Brånemark implants. Clin. Oral Implant. Res. 1993, 4, 151-157. [CrossRef]

39. Menini, M.; Conserva, E.; Tealdo, T.; Bevilacqua, M.; Pera, F.; Signori, A.; Pera, P. Shock absorption capacity of restorative materials for implant prostheses: An in vitro study. Int. J. Prosthodont. 2013, 26, 549-556. [CrossRef]

40. Smith, D.E.; Zarb, G.A. Criteria for success of osseointegrated endosseous implants. J. Prosthet. Dent. 1989, 62, 567-572. [CrossRef]

41. Choi, A.H.; Ben-Nissan, B. Bone Remodeling-Dental Implants. In Anatomy, Modeling and Biomaterial Fabrication for Dental and Maxillofacial Applications; Bentham eBooks, Ed.; Bentham Science Publishers, Random House Academic Marketing: New York, NY, USA, 2018; Volume 7, pp. 79-85.

42. Lin, G.H.; Chan, H.L.; Wang, H.L. The significance of keratinized mucosa on implant health: A systematic review. J. Periodontol. 2013, 84, 1755-1767. [CrossRef]

43. Lim, H.C.; Wiedemeier, D.B.; Hämmerle, C.H.; Thoma, D.S. The amount of keratinized mucosa may not influence peri-implant health in compliant patients: A retrospective 5-year analysis. J. Clin. Periodontol. 2019, 46, 354-362. [CrossRef]

44. Chung, D.M.; Oh, T.J.; Shotwell, J.L.; Misch, C.E. Wang HL. Significance of keratinized mucosa in maintenance of dental implants with different surfaces. J. Periodontol. 2006, 77, 1410-1420. [CrossRef] [PubMed]

45. Al-Abdaly, M.; Al-Harthi, H.; Al-Harthi, S.; Almalki, R. Oral Health Status and Gingival Response to Three Different Restorative Materials among Saudi Patients: A Clinical \& Histopathological Study. Int. J. Clin. Med. 2019, 10, 78-90.

46. Lazzara, R.J.; Porter, S.S.; Testori, T.; Galante, J.; Zetterqvist, L. A prospective multicenter study evaluating loading of Osseotite implants two months after placement: One-year results. J. Esthet. Dent. 1998, 10, 280-289. [CrossRef] [PubMed]

47. Nasatzky, E.; Gultchin, J.; Schwartz, Z. The role of surface roughness in promoting osteointegration. Refuat Hapeh Vehashinayim (1993) 2003, 20, 8-19.

48. Roehling, S.K.; Meng, B.; Cochran, D.L. Sandblasted and Acid-Etched Implant Surfaces With or Without High Surface Free Energy: Experimental and Clinical Background. In Implant Surfaces and Their Biological and Clinical Impact; Wennerberg, A., Albrektsson, T., Jimbo, R., Eds.; Springer: Berlin/Heidelberg, Germany, 2015.

49. Davies, J.E. Understanding peri-implant endosseous healing. J. Dent. Ed. 2003, 67, 932-949. [CrossRef]

50. Davies, J.E. Mechanisms of endosseous integration. Int. J. Prosthodont. 1998, 11, 391-401. [PubMed]

51. Alfarsi, M.A.; Hamlet, S.M.; Ivanovski, S. Titanium surface hydrophilicity enhances platelet activation. Dent. Mater. J. 2014, 33, 749-756. [CrossRef] [PubMed]

52. Barfeie, A.; Wilson, J.; Rees, J. Implant surface characteristics and their effect on osseointegration. Br. Dent. J. 2015, 218, E9. [CrossRef] [PubMed]

53. De Bruyn, H.; Christiaens, V.; Doornewaard, R.; Jacobsson, M.; Cosyn, J.; Jacquet, W.; Vervaeke, S. Implant surface roughness and patient factors on long-term peri-implant bone loss. Periodontol. 2000 2017, 73, 218-227. [CrossRef] [PubMed]

54. Doornewaard, R.; Christiaens, V.; De Bruyn, H.; Jacobsson, M.; Cosyn, J.; Vervaeke, S.; Jacquet, W. Long-term effect of surface roughness and patients' factors on crestal bone loss at dental implants. A systematic review and meta-analysis. Clin. Implant. Dent. Relat Res. 2016, 10, 372-399. [CrossRef] [PubMed]

55. Khang, W.; Feldman, S.; Hawley, C.E.; Gunsolley, J. A multi-center study comparing dual acid-etched and machined-surfaced implants in various bone qualities. J. Periodontol. 2001, 72, 1384-1390. [CrossRef]

56. Berglundh, T.; Persson, L.; Klinge, B. A systematic review of the incidence of biological and technical complications in implant dentistry reported in prospective longitudinal studies of at least 5 years. J. Clin. Periodontol. 2002, 29, 197-212. [CrossRef] [PubMed]

57. Lemos, C.A.A.; Verri, F.R.; Santiago Junior, J.F.; de Souza Batista, V.E.; Kemmoku, D.T.; Noritomi, P.Y.; Pellizzer, E.P. Splinted and Nonsplinted Crowns with Different Implant Lengths in the Posterior Maxilla by Three-Dimensional Finite Element Analysis. J. Healthc Eng. 2018, 2018, 3163096. [CrossRef]

58. Vigolo, P.; Mutinelli, S.; Zaccaria, M.; Stellini, E. Clinical evaluation of marginal bone level change around multiple adjacent implants restored with splinted and nonsplinted restorations: A 10-year randomized controlled trial. Int. J. Oral Maxillofac Implant. 2015, 30, 411-418. [CrossRef]

59. Pan, Y.; Tsoi, J.K.H.; Lam, W.Y.H.; Pow, E.H.N. Implant framework misfit: A systematic review on assessment methods and clinical complicatthe clinical complicationsions. Clin. Implant. Dent. Relat Res. 2021, 23, 244-258. [CrossRef] [PubMed]

60. Lin, C.Y.; Chen, Z.; Pan, W.L.; Wang, H.L. Is History of Periodontal Disease Still a Negative Risk Indicator for Peri-implant Health under Supportive Post-implant Treatment Coverage? A Systematic Review and Meta-analysis. Int. J. Oral Maxillofac Implants 2020, 35, 52-62. [CrossRef] [PubMed]

61. Schwarz, F.; Schär, A.; Nelson, K.; Fretwurst, T.; Flügge, T.; Ramanauskaite, A.; Trimpou, G.; Sailer, I.; Karasan, D.; Fehmer, V.; et al. Recommendations for Implant-Supported Full-Arch Rehabilitations in Edentulous Patients: The Oral Reconstruction Foundation Consensus Report. Int. J. Prosthodont. 2021, 34, 8-20. [CrossRef] [PubMed] 